\title{
TRAVESTILIDADES NÔMADES: A EXPLOSÃO DOS BINARISMOS E A EMERGÊNCIA QUEERING
}

\author{
Wiliam Siqueira Peres \\ Universidade Estadual Paulista, Assis
}

\begin{abstract}
Resumo: Apresentamos neste artigo algumas problematizações a respeito da expressão "travesti", que, não se apoiando em um modelo único de referência sexual e de gênero para sua efetivação, nos permitiria falar em processos de 'travestilização'. Esses processos se constituem através de dispositivos em que lineamentos duros, flexíveis e de fuga participam da criação de seus corpos, desejos e prazeres, transitando entre efeitos-consequências de discursos normativos e singularizadores. Sua circulação no mundo coloca em xeque as matrizes binárias heteronormativas do sistema sexo/gênero/desejo, que se desmancham diante de modos de subjetivação orientados por potências subversivas criadoras de novos campos possíveis de existencialização. Nessa perspectiva, queremos mostrar que as expressões sexuais e de gêneros das travestis formulam novas questões a respeito dos modelos identitários vigentes, demonstrando que a coerência e a inteligibilidade impostas pelos códigos heteronormativos precisam ser urgentemente revistas, de modo a questionar a respeito da ordem social que apresenta o gênero associado ao sexo reprodutivo, para ressignificar as expressões sexuais, gendradas e subjetivas, em sua processualidade histórica que explode os binarismos, despreza os universais e desmancha o absolutismo da ideia de verdade, enraizados nos sistemas binários de pensamentos sedentários, fechados, universais e a-históricos.
\end{abstract}

Palavras-chave: travestilidades; subjetividades; gêneros; binarismos; nomadismos.

Em seu último curso ministrado na Universidade de Berkeley, em 1984, sob o título Le courage de la vêrité, traduzido para o espanhol como Coraje y verdad, ${ }^{1}$ Michel Foucault coloca em análise o verbete "parrhèsía", clarificando que

[...] quem usa a parresía, o parresiasta, é alguém que diz tudo o que tem em mente: não oculta, nada, senão, que abre completamente seu coração e sua mente a outras pessoas mediante o discurso [...] na parresía, o parresiasta atua em consideração dos demais, mostrando-Ihes tão diretamente como é possível aquilo que realmente acredita

Copyright @ 2012 by Revista Estudos Feministas.

1 Tomás ABRAHAM, 2003. 
[...] A específica 'atividade discursiva' da enunciação parresiástica, portanto, toma a forma: sou quem pensa isto e isso, sou quem pensa isto e o outro. ${ }^{2}$

Trata-se de alguém que tem a coragem de dizer sobre si, de expressar uma posição social e política diante do mundo, das pessoas e de si mesmo, assumindo um lugar que lhe permita sentir-se bem, satisfazer seus desejos e construir uma estilística da existência que expresse sua singularidade humana, mesmo que isso signifique sofrer violações e violências e até mesmo correr riscos de vida.

É nesse lugar que vejo a emergência das travestilidades como processualidades em trânsitos situadas entre a afirmação de suas verdades, ousadas, corajosas e afirmativas de suas estilísticas da existência diante de determinações do sistema sexo/gênero/desejo/ práticas sexuais, ${ }^{3}$ que, como ferramentas de manutenção à heteronormatividade, impõem modelos de verdades absolutas e universais, assim como cristalizações identitárias demarcadas por códigos de inteligibilidades falocêntricos.

As travestis são pessoas que se constituem através de processos de subjetivação que oscilam entre discursos e figurações normatizadores que tentam disciplinar seus corpos e regular seus prazeres, inaugurando um novo campo por meio de movimentos de resistências e de enfrentamento ao biopoder. ${ }^{4}$ Essa emergência geopolítica de resistência trazida pelas travestis reflete as lutas e as conquistas políticas presentes no movimento social emancipatório, no qual travestis e transexuais de diversas partes do Brasil têm se tornado protagonistas.

As travestis são produzidas através de uma ordem dos discursos que se efetuam pelas resistências às lógicas binárias e universalizantes, assim como heteronormativa e falocêntrica, que expressam singularidades e inauguram nova estética da existência, apesar de muitas das travestis e transexuais ainda se situarem dentro do modelo heteronormativo e falocêntrico, logo binário e moral, que impõe como modelos de identificação relacional (afetivo, sexual e amoroso) os determinados pelo sistema sexo/gênero/desejo/práticas sexuais.

A nosso ver, uma perspectiva crítica de investigação e estudos sobre o universo das travestis e transexuais deverá priorizar análises que positivem sua expressão existencial e rompam definitivamente com os sistemas de pensamentos binários, sedentários e universalizantes, de modo a ampliar o debate e ressignificar conceitos e metodologias restritas à patologização da vida.

$\mathrm{Na}$ constituição e fluidez de seu território existencial, as travestis expressam singularidades possíveis em consequência de uma evolução criadora que faz das travestilidades ensaios de bem viver, de enfrentamento aos padrões normativos que insistem em se fixar em seus corpos, sensibilidades e pensamentos. No entanto, a respeito da constituição do território existencial, dirá Michel Foucault ${ }^{5}$ que "seu contorno não é obtido por uma linha que corre nítida ao longo do corpo, mas por milhões de traços perpendiculares, de pequenas palhas, que formam um eriçamento geral, uma sombria presença na noite".

Seguindo essa lógica, queremos problematizar a respeito dos processos de subjetivação que constroem as figurações travestis, que, para além dos discursos normatizadores e das estruturas sedentárias de pensamento, se orientam por referências nômades de significados, sentidos e narratividades, logo por modos de subjetivação nômades.

${ }^{2}$ Michel FOUCAULT, 2003, p. 266, tradução nossa.

3 Judith BUTLER, 2003.

4 FOUCAULT, 1988.

${ }^{5}$ FOUCAULT, 2010 , p. 85 
Partimos do pressuposto de que a subjetividade se processa no registro do social e, como tal, é sempre datada historicamente, atravessada por relações de saber/poder/prazer evidenciadas por lógicas discursivas que tanto podem normatizar como singularizar a fabricação dos sujeitos. Nesse sentido, a subjetividade não tem nada a ver com interioridade, com uma essência metafísica de constituição dos sujeitos, pois traz em seu bojo constituinte elementos de classe social, de raça/etnia, de sexo, de sexualidade, de orientação sexual, de gênero, de geração, de grupo, de nacionalidade, enfim, de multiplicidades que implicam uma dimensão rizomática que nos leva a pensar na constituição de sujeitos que não são 'uno', mas expressões de múltiplos devires.

Nesse sentido, as configurações rizomáticas nos permitem traçar cartografias que nos mostram as intensidades presentes nos lineamentos (duros, flexíveis e de fuga) que tanto podem normatizar os discursos, as corporalidades e os desejos quanto promover o direito fundamental à singularidade e suas possibilidades de ser, estar e circular no mundo.

Na perspectiva do indivíduo metafísico, os modos de subjetivação se apoiam em regras normativas que determinam identidades fixas, rígidas e cristalizadas que apresentam as pessoas como viciados em normas, dependentes de padrões hierarquizados e defensores da lei, dos contratos e das instituições regulatórias e disciplinares. Essa dimensão é escravizada pelos imperativos da heteronormatividade, que impõem a heterossexualidade de modo compulsório e se apoiam em um sistema sexo/gênero/desejo/práticas sexuais em que um indivíduo, ao nascer macho, seu gênero será masculino, seu desejo heterossexual e sua prática sexual ativa, enquanto que, caso nasça fêmea, seu gênero será feminino, seu desejo heterossexual e sua prática sexual passiva.

Qualquer expressão fora do circuito sexo/gênero tende a manter-se na invisibilidade ou ser tratada como criminosa e/ou pecadora e/ou anormal e/ou perversa, logo como abjeta. A abjeção se incumbe da desapropriação de qualquer reconhecimento ou direito que um ser humano possa ter por inexistir para a inteligibilidade lógica das compreensões normativas, ou seja, sem visibilidade não é reconhecido como sujeito, se não é sujeito não existe, logo não pode ser tomado como ser de direitos. Nessa perspectiva, concordamos com Larissa Pelúcio' quando escreve que "essa não existência acaba por colocar as travestis no plano do abjeto, corpos cuja existência parece não importar. De fato, importam, pois os abjetos precisam estar lá, ainda que numa higiênica distância, para demarcar as fronteiras da normalidade".

A manutenção do sistema sexo/gênero/desejo se efetiva através de toda uma fixação das ideias e dos conceitos dados como verdadeiros e universais, logo binários, e isso produz efeitos de normatização que atuam sobre todos os corpos (percepção, sensação, pensamentos, desejos e práticas), sejam eles masculinos e femininos, homossexuais e heterossexuais, travestis e transexuais.

As determinações normativas advindas do sistema sexo/gênero/desejo atuam tanto sobre os corpos orgânicos com seus sistemas perceptivos, cognitivos e sensoriais quanto em seus processos subjetivos. Nesse sentido, quando uma pessoa se expressa 'fora da ordem', há, muitas vezes, tendências de se recorrer a processos de culpabilização e de inferiorizaçao que acabam fazendo com que as pessoas se submetam às lógicas normativas e reproduzam os discursos e as imagens impostas pelo biopoder como únicas e absolutas.

As travestilidades, quando expressam singularidades, se efetuam pela perspectiva do nomadismo, pelos modos de subjetivação que se apoiam na diferença das diferenças, ou seja, a própria diferença é nômade, porque não se totaliza em uma marca identitária, mas se apresenta como fluxo; e, se por acaso ousarmos falar em identidade, será sempre

${ }^{6}$ Larissa PELÚCIO, 2009, p. 47. 
transgressora, transitória, razão pela qual está sempre aberta para novas conexões, para experimentações existenciais que se atualizam pelo viés da diversidade estética em suas variações, sociais, raciais, sexuais, culturais, gendradas, políticas, de modo a negociar a circulação e a ocupação tanto de territórios geopolíticos quanto de territórios existenciais.

\section{Territórios nômades da subjetividade: a emergência queer}

As travestis e suas estéticas surgem como figurações nômades privilegiadas dessa dimensão ampliada das diferenças, produzindo pensamentos e ideias em oposição às estruturas binárias e sedentárias do pensamento, que se organiza pelo falocentrismo e pelas normas disciplinares e reguladoras do sistema sexo/gênero. Essa perspectiva nos dá a ideia de sujeitos como processo, como subjetividades em construção permanente marcadas por situações concretas, situadas e regidas por políticas de localização que não se fixam e nem se cristalizam em identidades acabadas e definitivas; trata-se de sujeitos em trânsitos, em fluxo, logo sujeitos queer.

Seguindo nesse sentido, apostamos com Tamsin Spargo' que o que podemos considerar quando falamos de uma identidade, de um 'eu', um 'si', diz respeito a

[...] uma ficção socialmente construída (ainda que grave), um produto da linguagem e dos discursos específicos vinculados com as divisões de saber. Posso crer que sou singular e essencialmente eu mesmo e que estou comprometido no processo, permanente e frustrante, de tratar de expressar-me e de expressar minhas intenções e propósitos diante dos outros mediante a linguagem. Porém esta crença, esta sensação de individualidade e autonomia é, em si mesma, um constructo social e não o reconhecimento de um fato natural.

Trata-se de transitoriedades do eu, que vacila de acordo com valores, significados e discursos de cada época temporoespacial, que solicita políticas de localização que façam referência a uma forma de dar sentido à diversidade existente entre as travestis. De suas expressões amorosas, afetivas, sexuais e de gêneros, que fazem delas seres singulares que nada podem ser comparados com modelos normativos dados pelo sistema sexo/ gênero/desejo, pela heteronormatividade e/ou pelo falocentrismo. Trata-se de seres híbridos, particulares, que expressam estilísticas marginais do desejo e, por isso, solicitam outras formas de problematizações a respeito de si mesmos, colocando em crise as teorias psicossociais existentes, bombardeando os paradigmas sociais, políticos e culturais, produzindo novas demandas, novas perguntas e novas reivindicações de direitos humanos, sexuais, políticos, culturais e de gêneros.

As travestis inauguram um novo estilo de existência na contemporaneidade, marcado pela expressão de suas singularidades, e, por isso, produzem novas tomadas de consciência crítica, o que solicita mais discussões nas diversas esferas de convivência social, política e cultural, produzindo novas formas de perceber, sentir, pensar e agir com e no mundo que não se orientem pelos binarismos e pelos universalismos.

Sem perder de vista as referências discursivas normatizadoras, classificatórias e excludentes presentes nas expressões de algumas travestis, capturadas pela lógica binária e reducionista que as fazem repetidoras dos padrões normativos impostos como obrigatórios e absolutos em suas relações com o mundo, com as pessoas e consigo mesmas, o que chama nossa atenção e que ganha maior destaque diz respeito ao seu movimento de enfrentamento aos padrões estéticos, discursivos e desejantes impostos pelas biopolíticas regulatórias, que bate de frente com instituições antigas e conservadoras, como é o caso do Estado, da Igreja, da medicina, do direito, da família, entre outras.

${ }^{7}$ Tamsin SPARGO, 2004, p. 65, tradução nossa. 
O processo de constituição das subjetividades demanda registros de complexidades tanto em termos sociais, sexuais, como de gêneros, de classe, de raça, de estéticas, evidenciando que as referências que as estigmatizam, discriminam, violentam e excluem não fazem mais sentido como categorias de análises; torna-se necessário que a questão da diferença entre as diferenças seja tomada como afirmativa, ativa, transitória e potente, como figurações nômades que participam da construção do sujeito coletivo e emancipado. Os deslocamentos nômades designam um estilo criativo de transformação, como metáforas performativas que permitem novos encontros e conexões que ampliam os universos de referências sobre o humano, suas experimentações e a aquisição de novos conhecimentos e práticas existenciais - novas cartografias existenciais.

De acordo com Rosi Braidotti, ${ }^{8}$ o nômade não representa a falta de um lugar nem o deslocamento compulsivo; é uma figuração do tipo de sujeito que tem renunciado a toda ideia, desejo ou nostalgia do estabelecido, do dado normativo. Essa figuração evidencia o desejo de uma expressão feita de transições, de deslocamentos sucessivos e descontínuos, sem uma unidade, um eixo condutor ou núcleo essencial. No entanto, o sujeito nômade não está completamente desprovido de unidade: seu modo é o de padrões categóricos, de movimentos através de caminhos estabelecidos engendrados por repetições de movimentos intermitentes, rítmicos, de composições múltiplas e descontínuas. Nesse sentido, o nômade tem a ver com cruzar fronteiras, com o ato de ir, independentemente do tipo e/ou sentido da viagem. Diria Gilles Deleuze e Félix Guattari, ${ }^{9}$ em seu Tratado de nomadologia, que a vida do nômade é um intermezzo... O nômade é um vetor de desterritorialização, não classificável, não redutível, não cristalizado.

O nômade é a própria figuração de uma interpretação situada, transcontemporânea, culturalmente diferenciada do sujeito em geral e do sujeito dissidente em particular; na medida em que eixos de diferenciação, tais como classe, raça, gênero, idade e outros, entrem em intersecção e interação entre si para constituir a subjetividade, a noção de nômade se refere à presença simultânea de muitos de tais eixos: potentes, intempestivos, intensos, produtores de sujeitos híbridos, múltiplos e diversos.

Consideramos que as figurações estéticas, políticas e culturais expressas pelas travestilidades solicitam novas formas de existencialização. Levando em conta, ainda, que as referências de análises estão comprometidas com as estruturas binárias, sedentárias e universalistas de pensamento, como problematizar a respeito das reivindicações por direitos a ter direitos engendrados pelas travestis - considerando que essas são demandadas em um mundo marcado pelo sistema sexo/gênero/desejo, pelo falocentrismo e pela heteronormatividade - e como escapar de suas armadilhas?

Essas questões abrem-se para outras questões que dizem respeito à emergência de novos sujeitos de direitos que reivindicam outras referências e posicionamentos diante da vida, solicitando revisão das categorias analíticas que colocam as travestilidades associadas com a doença, com o pecado, com o crime, com a abjeção; as travestis não se reduzem a isso!

Para problematizar a esse respeito, buscamos a ideia de 'sujeitos nômades', já apresentada mais acima. Partimos das propostas de Braidotti, ${ }^{10}$ que, embora problematize a respeito da categoria "mulher", pode nos auxiliar nessa empreitada, dada a relação intrínseca entre travestilidades e feminilidades, permitindo aproximações profícuas.

${ }^{8}$ ROSI BRAIDOTII, 2000

9 Gilles DELEUZE e Félix GUATTARI, 1997.

${ }^{10}$ BRAIDOTII, 2000 
De modo direto, para problematizar a ideia de sujeitos nômades, também somos levados a pensar em processos de subjetivação nômades que se apresentam em oposição às perspectivas dos modos de subjetivação normatizador. Braidotti informa que o ponto de partida da maior parte das redefinições feministas da subjetividade é uma nova forma de materialismo que desenvolve o conceito de materialidade corporal, colocando ênfase na estrutura corporificada, portanto, sexualmente diferenciada do sujeito falante. Braidotti (re)concebe as raízes corporais da subjetividade como ponto de partida para iniciar um projeto epistemológico de nomadismo - o corpo. A corporificação do sujeito não deve ser entendida somente como uma categoria biológica nem como uma categoria sociológica, mas como um ponto de superposição entre o físico, o subjetivo e o sócio-histórico, repudiando radicalmente o essencialismo.

Trata-se de linhas de subjetivação que produzem no corpo materializações de discursos reguladores evidenciados tanto nos estudos de Braidotti ${ }^{11}$ como nos de Judith Butler, com a noção de performatividade entendida como

a prática reiterativa e referencial mediante a qual o discurso produz os efeitos que nomeia [...] as normas reguladoras do 'sexo' trabalham de uma maneira performativa para constituir a materialidade dos corpos, e, mas especificamente, para materializar o sexo do corpo, para materializar a diferença sexual de modo a consolidar o imperativo heterossexual. $^{12}$

O sujeito nômade aparece, assim, como uma forma possível de romper com esses processos performativos, ao mesmo tempo que esse sujeito é um mito, uma ficção política que permite analisar detalhadamente as categorias estabelecidas e os níveis de experiências e deslocamentos estabelecidos por eles: borrar as fronteiras sem desmanchar as pontes de conexão. Isso implica acreditar na potência e na relevância da invenção, na construção de mitos, como um modo de êxtase política e intelectual desses tempos transcontemporâneos. Como nos alertam Deleuze e Guattari, ${ }^{13}$ todas as entradas são boas desde que as saídas sejam múltiplas.

Ainda que a imagem dos sujeitos nômades esteja inspirada na experiência do nomadismo, do deslocamento constante de lugar característico de determinados povos, a questão aqui se refere ao tipo de consciência crítica que resiste estabelecer-se nos modos socialmente codificados de pensamentos e condutas. O que define o estado nômade é a subversão às convenções estabelecidas, e não o ato literal de viajar. $O$ esquema de pensamento apresentado por Deleuze e Guattari ${ }^{14}$ resiste às tentações românticas e implica uma dissolução total da ideia de centro, de noções de lugares originários ou de identidades autênticas de qualquer tipo. Esses autores nos advertem contra o risco de que os sistemas pós-modernos, com sua fragmentação e sua perda de unidade, possam reproduzir globalmente as relações de poder em pequenas escalas, como os microfascismos: formações de poder menores, mais localizadas, igualmente explosivas, caracterizadas pela reprodução de hegemonias disseminadas, em uma escala global. Uma epistemologia nômade radical diz respeito a uma forma de resistência ao microfascismo, na medida em que solicita um distanciamento qualitativo dessas hegemonias, ainda que tenha um alcance local.

O sujeito nômade como figura ampliada permite entrelaçar diferentes níveis de experiência, os quais refletem alguns aspectos autobiográficos e expressam ao mesmo

11 BRAIDOTTI, 2000 e 2005.

12 BUTLER, 2002, p. 18, tradução nossa.

${ }^{13}$ DELEUZE e GUATTARI, 1995.

14 DELEUZE e GUATTARI, 1997.

544 Estudos Feministas, Florianópolis, 20(2): 539-547, maio-agosto/2012 
tempo uma preferência conceitual por uma visão pós-metafísica da subjetividade. Para Braidotti, ${ }^{15}$ esse tipo de figura do sujeito nômade lhe permite conjugar um modo de política sexual e de gênero com uma variedade de outras preocupações culturais e epistemológicas, como explorar o enfoque performativo do nomadismo e a riqueza metafórica presente nas experiências de prazer, indagando sobre algumas ressonâncias cognitivas e afetivas da imagem do nômade, nem sempre previsíveis.

As vivências de diferentes níveis de experiência que promovem as diversas figurações, discursos e desejos que compõem as travestilidades remetem à ideia da existência de pessoas, de um plano concreto de vidas reais que diferem do imediato normativo, mas que, por outro lado, também são atravessadas por dispositivos que operam na construção de estruturas de pensamentos previamente constituídos pelo sistema sexo/gênero/desejo em uma perspectiva falocêntrica e heteronormativa. Esse modo de pensamento "opera dentro de uma construção que não apenas faz dos indivíduos o ponto de partida para o conhecimento, como também naturaliza categorias como homem, mulher, preto, branco, heterossexual ou homossexual ao tratá-las como características inerentes aos indivíduos". 16

De acordo com Joan Scott, ${ }^{17}$ os sujeitos, em vez de terem experiências, seriam constituídos através delas, normatizados por modelos e discursos previamente dados, porém com o livre-arbítrio de criar e inventar novos modos de existencialização, de resistência e de enfrentamento ao biopoder. Ainda a respeito da experiência, Teresa de Lauretis, citada por Scott, ${ }^{18}$ dirá que esse

é o processo pelo qual, para todos os seres sociais, a subjetividade é construída. Através desse processo a pessoa se coloca ou é colocada na realidade social, e, assim, percebe e compreende como subjetivas (que se originam no indivíduo e se refere a ele próprio) aquelas relações - materiais, econômicas e interpessoais - que são, de fato, sociais, e, numa perspectiva maior, históricas.

Nessa perspectiva podemos perceber relações intrínsecas entre a experiência vivida pelas travestis em seus territórios geopolíticos existenciais e os significados e valores que são atribuídos às figurações, aos discursos e aos desejos que se processam em decorrência da própria experiência de vida, demarcando preconceitos e exclusões, se analisados através das estruturas binárias e sedentárias de pensamento. Mas são também essas mesmas experiências que possibilitam expressões corporais, sociais, sexuais, de gênero, políticas e culturais, que evidenciam a emergência de potências subversivas que implodem os binarismos e desmancham os universais.

Os sujeitos nômades são capazes de se liberarem do jogo falocêntrico binário e restituir sua liberdade de escolha e criação, vivacidade e beleza. Há uma profunda dimensão estética na busca de figurações nômades alternativas, e a travestilidade, revertendo a ordem binária e sedentária das imagens constitutivas do pensamento em prol de outra composição de referências nômades, contribui para que essa dimensão possa ser empiricamente percebida.

As imagens do pensamento sedentário tendem a se conectar com a memória. A recomendação nietzschiana nos alerta sobre o quão maligna pode ser a memória se considerarmos que ela traz lembranças que, por sua vez, produzem ressentimentos e os ressentimentos se encarregam de produzir más consciências. ${ }^{19}$

${ }^{15}$ BRAIDOTTI, 2000

16 Joan SCOTT, 1999, p. 30

17 SCOTT, 1999.

${ }^{18}$ Teresa DE LAURETIS citada por SCOTT, 1999, p. 31

19 Friedrich NIETZSCHE, 1987. 
Em uma perspectiva do pensamento nômade, não se trataria da memória ligada à formação do indivíduo nem daquela advinda da psicanálise, pois essas estão descomprometidas com identidades e cristalizações. Imagem do pensamento, desejos e devires são nômades e não ocupam um ponto fixo predeterminado, são fluxos intempestivos e potentes.

De acordo com Guattari, ${ }^{20}$ esses fluxos se estendem sobre o território liso e aberto de modo a ocupar seus espaços sem se fixar como uma raiz, sempre escorregando de um ponto a outro e inventando nomadismos como resposta a outras forças que insistem na manutenção dos binarismos normatizantes.

A inserção das travestis e as travestilidades no registro do nomadismo inauguram novos modos possíveis de pensamento e de existencialização, o que implica novas questões sociais, políticas e culturais que precisam ser problematizadas fora do registro binário e universal para compor-se com o múltiplo, o diverso, o diferente; na perspectiva nômade, há um convite para des-pensar a dicotomia masculino/feminino e a dualidade metodológica e analítica, pois já não existe mais um modelo único e universal, estruturado e estruturante, o que há são pluralidades, polifonias, devires, rizomas.

Há um território, há sempre um território demarcado por biopolíticas regulatórias que, através de discursos morais e assépticos, produzem os espaços possíveis, normatizados, esquadrinhados, serializados. Há outros territórios, há sempre outros territórios possíveis que se processam através de resistência e enfrentamento das lógicas normativas, que constroem outros possíveis, multiplicidades, descontinuidades, diferenças. Há urgências de revisão teóricas e metodológicas binárias que permitam analises out das tradicionais disponíveis e assim criar novos olhares sobre as travestis, em uma perspectiva da estilística da existência, do respeito às expressões que ousam expressar-se como potentes e parresiastas.

\section{Referências}

ABRAHAM, Tomás. El último Foucault. Buenos Aires: Editorial Sudamericano, 2003.

BRAIDOTTI, Rosi. Sujetos nómades. Buenos Aires: Editorial Paidós, 2000. 2005.

. Feminismo, diferencia sexual y subjetividad nómade. Barcelona: Editorial Gedisa,

BUTLER, Judith. Cuerpos que importan: sobre los límites materiales y discursivos del "sexo". Buenos Aires: Editorial Paidós, 2002.

Problemas de gênero: feminismo e subversão da identidade. Rio de Janeiro: Civilização Brasileira, 2003.

DELEUZE, Gilles; GUATTARI, Félix. Introdução: rizoma. São Paulo: Editora 34, 1995. (Mil Platôs, V. 1).

. Tratado de nomadologia: a máquina de guerra. São Paulo: Editora 34, 1997. (Mil Platôs, v. 5).

GUATTARI, Félix. Caosmose: um novo paradigma estético. Rio de Janeiro: Editora 34, 1992.

FOUCAULT, Michel. História da sexualidade: a vontade de saber. Rio de Janeiro: Graal, 1988. v. 1.

"Coraje y verdad". In: ABRAHAM, Tomás. El último Foucault. Buenos Aires: Editorial Sudamericano, 2003. p. 265-406.

. A força de fugir: ditos \& escritos VI. Rio de Janeiro: Forense Universitária, 2010.

NIETZSCHE, Friedrich. Genealogia da moral: um escrito polêmico. São Paulo: Brasiliense, 1987.

${ }^{20}$ GUATTARI, 1992.

546 Estudos Feministas, Florianópolis, 20(2): 539-547, maio-agosto/2012 
PELÚCIO, Larissa. Abjeção e desejo: uma etnografia travesti sobre o modelo preventivo de aids. São Paulo: Annablume, 2009.

SCOT, Joan. "Experiência". In: LAGO, Mara Coelho de Souza; RAMOS, Tânia Regina Oliveira; SILVA, Alcione Leite (Org.). Falas de gênero. Florianópolis: Mulheres, 1999. p. 31. SPARGO, Tamsin. Foucault y la teoria queer. Barcelona: Gedisa, 2004.

Nomad Transvestilities: The Explosion of Binarism and the Queering Urging

Abstract: By not relying on a single sexual and gender model of reference to be effective, we aim at problematizing the transvestite expression. Such specificity would allow us to talk about 'transvestilization' processes. These processes are constituted through devices in which tough, flexible and leak lines participate in the creation of their bodies, desires and pleasures. This creation transits among normative and singularized discourses effects/consequences. The transvestites transit in the world, challenging the binary heteronormative matrices of the sex/ gender/desire system. Such system fails in relation to modes of subjectivity oriented by subversive power, which create new possible territories of existence. In this perspective, our goal is to demonstrate that transvestites' sexual and gender expression generate new questions about the current identity models. This questioning demonstrates that the coherence and the intelligibility imposed by heteronormative codes need to be urgently reviewed in order to question the sociall order presented by the splitting gender in reproductive sex. It also seems to be important to reframe the generic and subjective sexual expressions in its historical processuality, which explode the binaries, despise the universal and liquefy the absolutism of the idea of truth; an idea rooted in binary systems of settled, closed and universal ahistorical thoughts.

Key Words: Transvestilities; Subjectivity; Gender; Binarism; Nomadism. 